\title{
Tactual and auditory vigilance in split-brain man
}

\author{
S T U A R T J. D I M O N D \\ From the Department of Psychology, University College, Cardiff
}

SUM MARY Two studies are reported of tactual and auditory vigilance performance in patients with a split-brain or partial commissurotomy to examine the attentional behaviour of the right and left hemisphere, and to identify defects in attention which may be related to the division of the cerebral commissures. The performance of the right hemisphere on all tasks of sustained attention so far studied was substantially better than that of the left. Considerable depletion of concentration was observed for the total split-brain group but not in patients with partial commissurotomy. One of the more unusual phenomena of the split-brain condition is that gaps of attention, often lasting many seconds, occur predominantly on the left hemisphere. The switch to a different type of signal on the same hemisphere does not stop them but the switching of signals from one hemisphere to another does. The defect is interpreted as a failure of attention peculiar to the individual hemisphere under test.

It has long been noted that the power of concentration of split-brain man is poor. Sperry (1974) states that "one gets a general impression from working with these (split-brain) patients over long periods that their overall mental potential is affected by the commissurotomy. Perseverance in tasks that are mentally taxing remains low in most of the patients as does the ability to grasp broad long-term or distant implications of a situation." Zangwill (1974) suggests that "section of the cerebral commissures has the twin consequences of depleting the attentional capacity of each hemisphere as well as largely abolishing integration between them."

The method I have used to study concentration in split-brain man is a traditional vigilance procedure (Dimond, 1976a,b; 1977). The patient is required to maintain watch for signals which occur relatively infrequently, performance being required over protracted periods of time. On a test of visual vigilance performance which used a divided visual field to test separately the functions of the two hemispheres, a gross depletion of attentional capacity was discovered for split-brain man which was absent in partial commissurotomy patients. The left hemisphere showed poorer performance than the right with many protracted gaps in its relationship to the stimulus.

Address for reprint requests: Dr S. J. Dimond, Department of Psychology, University College, Cardiff CF1 1XL.

Accepted 4 July 1978
In this paper I describe studies of tactual and auditory vigilance in split-brain man and partial commissurotomy patients undertaken to discover whether this depletion of attentional capacity is observed in both groups, whether it relates to complete or partial section, and whether different modes of hemisphere function are to be observed on tasks other than visual ones.

\section{Subjects}

Of the six total commissurotomy patients tested all had complete section of the corpus callosum, hippocampal, and anterior commissures. The massa intermedia was also sectioned in patients NG and NW (Bogen et al., 1965). The surgical approach to the anterior commissure involved the columns of the fornix. The operation was undertaken for the relief of severe and progressive epileptic attacks. The case histories have been fully described by Bogen and Vogel (1974) together with evidence of the present neurological status.

Two patients with partial commissurotomies were also tested (Table 1). One patient was tested in whom only the anterior two-thirds of the corpus callosum was sectioned together with the anterior commissure, sparing the splenium. This case is described by Gordon et al. (1971). Another patient was tested in whom the middle third of the corpus callosum had been sectioned for the treatment of an underlying angioma (Dimond et al., 1977).

All the patients described, except the last, 
Table 1 Patients' ages at test and number of years since operation

\begin{tabular}{llll}
\hline Category of operation & Patients & $\begin{array}{l}\text { Age } \\
\text { tested } \\
(y r)\end{array}$ & Years since operation \\
\hline Complete commissurotomy & NG & 42 & 11 \\
& CC & 24 & 11 \\
& NW & 45 & 9.5 \\
& RY & 52 & 10 \\
& LB & 24 & 11 \\
& AA & 25 & 11.5 \\
Partial commissurotomy & NF & 34 & 7.5 \\
& PA & 24 & 2 \\
\hline
\end{tabular}

suffered from severe longstanding epilepsy before surgery, and were, at the time of testing on mild to moderate anticonvulsive medication. Extracallosal damage not associated with surgery was probably present in all cases, varying widely in extent but thought to be minimal in patients LB and NG (Zaidel and Sperry, 1974).

\section{Method}

Studies of vigilance performance-auditory and tactual-were conducted on each patient. The methods used previously in the investigation of split-brain man (Sperry, 1974) were used here to lateralise vigilance tasks to the two hemispheres so that comparison could be made between them. The subject's task was to detect signals given to the right or the left hemisphere. The essence of the vigilance procedure is for performance to be maintained over protracted periods of time, and for the subject to keep watch for signals which occur only infrequently. In the studies reported here considerations of care for the patient limited the period of experimental investigation of each test to 30 minutes. It may be argued, therefore, that this was not a true vigilance experiment. The performance of split-brain man, however, over this period showed a gross vigilance decrement which serves further to highlight the difference between this and the normal performance (Dimond and Beaumont, 1973).

The general procedure was first to administer eight pretraining signals, four on each hemisphere, randomly distributed and at the same rate as the experimental trials to ensure an adequate initial level of response. During the subsequent $30 \mathrm{~min}$ test period, 60 signals were given distributed equally but according to a randomised schedule between the hemispheres. The signal was presented at a varied interval. The mean intersignal interval was 30 seconds, the range varying between 20 and 40 seconds. Because the duration of the task was short by the standard of traditional tasks and, in order to get as much information as possible about the subject's performance, if the subject failed to detect one of these initial signals the signal would repeat itself at $1.5 \mathrm{~s}$ intervals until detection had occurred or until 10 such signals had occurred without response. False positive responses were scored if the response occurred more than $10 \mathrm{~s}$ after the last signal and more than five seconds before the next signal. This basic procedure was followed in each of the separate testing sessions, for tactual and auditory vigilance.

\section{TACTUAL TASK}

Perhaps the most successful method of achieving lateralisation to one or other hemisphere is to require the subject to perform a tactual task with signals distributed to each hand. To study the tactual vigilance of each hand we devised a vibratotactual task. The patient placed both hands through the lower part of a screen which acted to shield the hands from vision. The index finger of each hand was placed on a moving coil which was the instrument providing the vibrato-tactual signal. The metal coil was a moving coil from a headphone insert mounted in a zinc metal box $6 \times 11 \times$ $3 \mathrm{~cm}$. The signals were given in a range below that of auditory frequency. In addition, the coil was rubber-mounted to prevent auditory signals, and the patient wore New Sonic stereo headphones, again to inhibit auditory cues. Tests conducted before the vigilance run showed that signals could not be detected other than through the fingers placed on the coil. The coil disc measured $28 \mathrm{~mm}$ across. The signal was applied to the coil by a Farnell LFM 3 signal generator. The signals could be switched to the left hand, the right hand, or to both hands together. The amplitude of the signal was adjusted by a small signal amplifier, and initial adjustment made for each patient at the beginning of the experiment to ensure that the signal level was appropriate to produce a full initial response. The patient rested the index finger of each hand on the mounted coil disc. Each signal consisted of a sine-wave vibration of the disc at the rate of $10 \mathrm{~Hz}$ starting at any point in the cycle. The signal duration was $350 \mathrm{~ms}$ of disc vibration. The patient's task was to detect the vibration of the disc and to depress the disc as soon as he felt the signal. The patient responded with his left hand to signals to the left index finger and with his right hand to signals to the right index finger.

\section{AUDITORY TASK}

The subject was seated comfortably at the apparatus. The hands were placed through the lower part of a screen where they rested on response 
buttons. The subject's task was to respond to a left side signal by pressing the left hand response button and a right signal by pressing the right hand response button. The subjects wore New Sonic stereo headphones. The auditory equipment consisted of a signal generator (Farnell LFM 3) and an amplifier built in our own workshops to provide a tone of $450 \mathrm{~Hz}$ for $100 \mathrm{~ms}$. The tone could be switched through to the left or the right ear. The vigilance task was to detect auditory signals of this type as they occurred on either ear and to press the corresponding response button. This task was performed according to the programme already described for $30 \mathrm{~min}$ in total. Signals were distributed randomly but with equal frequency across the two ears. Signals occurred on average every 30 seconds and were repeated as described previously in the absence of detection (a maximum of 10). Pretraining trials were given, and the amplification level was set so that the signals were well within the range of audibility.

\section{Results}

Performance on the right hemisphere was substantially better than that on the left. The results of the tactual task are given in Table 2 which shows detection as a response to the initial signal. An average of $37.5 \%$ signals were detected on the right whereas $23.5 \%$ were detected on the left. A Friedman two-way analysis of variance shows this difference to be significant $\left(\mathrm{Xr}^{2}=38.3 \mathrm{df}=1\right.$, $P=0.00013)$. This result was reinforced by examination of the number of additional signals required to prompt the hemisphere into actionmany additional signals were required on the left hemisphere (Table 2). One patient (AA) stood out from the others but he is known to have some motor problem affecting performance of the hands.

The results on auditory functions are not as clear (Table 3), although the advantage of the right hemisphere can still be observed. The right hemisphere score was $45.3 \%$ initial detections, and

Table 2 Tactual vigilance percentage signals detected by right and left cerebral hemispheres on initial signal presentation

\begin{tabular}{|c|c|c|c|c|c|}
\hline \multirow[t]{2}{*}{ Category of operation } & \multirow[t]{2}{*}{ Patients } & \multirow[t]{2}{*}{$\begin{array}{l}(50 \%) \\
\text { Left hemisphere } \\
\text { (right hand) }\end{array}$} & \multirow[t]{2}{*}{$\begin{array}{l}(50 \%) \\
\text { Right hemisphere } \\
\text { (left hand) }\end{array}$} & \multicolumn{2}{|c|}{$\begin{array}{l}\text { Performance scores of right and left } \\
\text { cerebral hemispheres. Number of } \\
\text { additional signals given (up to a maximum } \\
\text { of } 10) \text { during } 30 \text { min task performance }\end{array}$} \\
\hline & & & & $\begin{array}{l}\text { Left hemisphere } \\
\text { (right hand) }\end{array}$ & $\begin{array}{l}\text { Right hemisphere } \\
\text { (left hand) }\end{array}$ \\
\hline \multirow[t]{2}{*}{ Total commissurotomy } & $\begin{array}{l}\text { NW } \\
\text { CC } \\
\text { RY } \\
\text { AA } \\
\text { NG } \\
\text { LB }\end{array}$ & $\begin{array}{l}26.2 \\
25 \\
18.3 \\
30 \\
31.6 \\
10\end{array}$ & $\begin{array}{l}45 \\
28.3 \\
31.5 \\
25 \\
48.3 \\
45\end{array}$ & $\begin{array}{r}100 \\
57 \\
94 \\
93 \\
70 \\
186\end{array}$ & $\begin{array}{r}18 \\
32 \\
56 \\
50 \\
2 \\
4\end{array}$ \\
\hline & Average & 23.5 & 37.5 & 100 & 27 \\
\hline Partial commissurotomy & $\begin{array}{l}\text { NF } \\
\text { PA }\end{array}$ & $\begin{array}{l}50 \\
50\end{array}$ & $\begin{array}{l}50 \\
50\end{array}$ & $\begin{array}{l}\mathbf{0} \\
\mathbf{0}\end{array}$ & $\begin{array}{l}\mathbf{0} \\
\mathbf{0}\end{array}$ \\
\hline
\end{tabular}

Table 3 A uditory vigilance: percentage signals detected by right and left cerebral hemispheres on initial signal presentation

\begin{tabular}{|c|c|c|c|c|c|}
\hline \multirow[t]{2}{*}{ Category of operation } & \multirow[t]{2}{*}{ Patients } & \multirow[t]{2}{*}{$\begin{array}{l}(50 \%) \\
\text { Left hemisphere } \\
\text { (right ear) }\end{array}$} & \multirow[t]{2}{*}{$\begin{array}{l}(50 \%) \\
\text { Right hemisphere } \\
\text { (left ear) }\end{array}$} & \multicolumn{2}{|c|}{$\begin{array}{l}\text { Performance scores of right and left } \\
\text { cerebral hemispheres. Number of } \\
\text { additional signals given (up to a maximum } \\
\text { of } 10 \text { ) during } 30 \text { min task performance }\end{array}$} \\
\hline & & & & $\begin{array}{l}\text { Left hemisphere } \\
\text { (right ear) }\end{array}$ & $\begin{array}{l}\text { Right hemisphere } \\
\text { (left ear) }\end{array}$ \\
\hline \multirow[t]{2}{*}{ Total commissurotomy } & $\begin{array}{l}\text { NW } \\
\text { CC } \\
\text { RY } \\
\text { AA } \\
\text { NG } \\
\text { LB }\end{array}$ & $\begin{array}{l}11.6 \\
31.6 \\
43.3 \\
50 \\
45 \\
50\end{array}$ & $\begin{array}{l}23.3 \\
50 \\
50 \\
50 \\
48.6 \\
50\end{array}$ & $\begin{array}{r}61 \\
48 \\
10 \\
0 \\
10 \\
0\end{array}$ & $\begin{array}{r}37 \\
\mathbf{0} \\
\mathbf{0} \\
\mathbf{0} \\
\mathbf{2} \\
\mathbf{0}\end{array}$ \\
\hline & Average & 38.5 & 45.3 & 21.5 & 6.1 \\
\hline Partial commissurotomy & NF & 48.6 & 50 & 2 & $\mathbf{0}$ \\
\hline
\end{tabular}


the left hemisphere $38.5 \%$. When the number of additional signals to evoke response was considered, over three times as many signals were necessary on the left than on the right (Table 3). Two patients scored $100 \%$ on this task, and the overall depletion was not nearly as severe as on the tactual task.

Table 4 shows the striking overall depletion in vigilance performance in split-brain patients compared with partial commissurotomy patients. Performance analysed by time on the tactual and auditory tasks was compared with lateralised visual performance for which these patients were examined previously (Dimond, 1976a). Some depletion was present on each task for the split-brain person, visual function being the most affected, and auditory function the least. The partial commissurotomy patient showed virtually no depletion. This performance is in line with that of three normal individuals who showed no loss of performance whatsoever when tested on these tasks.

Table 4 Percentage detections during each 10 minute performance of the task: comparison of visual, tactual, and auditory performance.

\begin{tabular}{llllll}
\hline $\begin{array}{l}\text { Category of } \\
\text { operation and } \\
\text { of response }\end{array}$ & $\begin{array}{l}\text { Number } \\
\text { of } \\
\text { cases }\end{array}$ & 0 & $10 \mathrm{~min}$ & $20 \mathrm{~min}$ & $30 \mathrm{~min}$ \\
\hline $\begin{array}{l}\text { Total commissurotomy } \\
\quad \text { Visual }\end{array}$ & 6 & 100 & 54 & 46 & 30 \\
$\quad$ Tactual & 6 & 100 & 66.5 & 53 & 60 \\
Auditory & 6 & 100 & 90.5 & 82.5 & 78 \\
$\begin{array}{l}\text { Partial commissurotomy } \\
\text { Visual }\end{array}$ & 2 & 100 & 100 & 96 & 96 \\
Tactual & 2 & 100 & 100 & 100 & 100 \\
Auditory & 1 & 100 & 100 & 95 & 100 \\
\hline
\end{tabular}

One reason why the performance of the left hemisphere is so poor is that many gaps occur where the whole sequence of 10 repeated signals is presented without evoking any response. When the number of gaps of 10 signals without response are considered there were three on the tactual task for the right hemisphere but 40 for the left. With auditory signals, only one patient (CC) produced gaps of over five signals in length, and these occurred only on the left hemisphere. Gaps of this kind emerged as an interesting phenomenon of the results, and I wanted to discover if they extended across both sides of the brain or were confined to the hemisphere under test. If the patient had already received five signals without response on some selected trials a switch was made to the opposite hemisphere. The effect of this was almost always to obtain a response from the new hemisphere whereas continuation with the previous hemisphere frequently failed to do so. This suggests that the gap is confined to the hemisphere and does not extend across the whole brain.

The second question was whether the hemisphere can be brought out of a gap by a different kind of stimulus. On a few occasions towards the end of the tactual task, when the subject was failing to respond to the tactual signals (up to five), a tone was played without previous warning on the ear contralateral to the hemisphere under test. The effect of this was negative, and on one occasion a bilateral startle response was produced but the hemisphere under test still failed to begin producing responses. This, of course, refers to the left hemisphere which produced gaps sufficient in number to permit their study in this way. Thus even an unusual and powerful stimulus seems insufficient to reactivate the response from the hemisphere at these times.

The picture with regard to false positive results is confused. False positives were virtually absent from the tactual task. On the auditory task right hand false positives (18) were more frequent than left hand (2). This does not, however, conform with the visual results reported earlier (Dimond, 1976a) where the reverse was found.

\section{Discussion}

Depletion of vigilance performance in split-brain man is confirmed by these results. Performance occurred at a low level compared with partial commissurotomy patients and normal individuals, and there was a depletion for all modalities. This suggests that the corpus callosum forms an integral part of the system which organises attentional capacity, and gross defects in its production are to be observed after surgery upon it. Patients in whom the splenium is preserved remain free of any overall depletion.

Differences in the response between the hemispheres are clearly apparent. The percentage of signals detected by the left hemisphere is greatly diminished, the number of extra signals necessary to stimulate it into action is greatly increased. A striking feature of the results for tactual vigilance, although less so for auditory function, is in the number of protracted gaps which occur towards the middle and end of the task with increasing frequency on the left hemisphere. Their presence is interpreted as a difference in the powers of mental concentration between the two hemispheres in split-brain man. The left is apparently robbed of the power of concentration as the result of the surgery, whereas this continues, although somewhat diminished, in the right hemisphere. 
This research was conducted while I was in receipt of a NATO Senior Scientist Fellowship at the California Institute of Technology, Pasadena. The work was supported in part by a US Public Service grant MH-03372 National Institute of Mental Health to Dr R. W. Sperry. I would like to thank Lois McBird for her help in the conduct of this experiment. I make grateful acknowledgement to Dr Roger Sperry for his help, for the value of his experience, and for allowing me access to the commissurotomy patients described in this paper.

\section{References}

Bogen, J. E., and Vogel, D. J. (1974). Neurologic status in the long term following complete cerebral commissurotomy. In Les syndromes de disconnexion calleuse chez l'homme. Colloque International de Lyon 1974, pp. 227-252. Edited by F. Michel and B. Schott. SPCM: Lyon.

Bogen, J. E., Fisher, E. D., and Vogel, P. J. (1965). Cerebral commissurotomy: a second case report. Journal of the American Medical Association, 194, 1328-1329.

Dimond, S. J., and Beaumont, J. G. (1973). Differences in the vigilance performance of the right and left hemispheres. Cortex, 9, 259-265.
Dimond, S. J. (1976a). Depletion of attentional capacity after total commissurotomy in man. Brain, 99, 347356.

Dimond, S. J. (1976b). Brain circuits for consciousness. Brain Behaviour and Evolution, 13, 376-396.

Dimond, S. J. (1977). Vigilance and split-brain research. Paper presented to the NATO Vigilance Symposium. Plenum Press: New York.

Dimond, S. J., Scammell, R. E., Brouwers, E. Y. M., and Weeks, R. (1977). The functions of the centre section (trunk) of the corpus callosum in man. Brain, 100, 543-562.

Gordon, H. W., Bogen, J. E., and Sperry, R. W. (1971). Absence of disconnexion syndrome in two patients with partial section of the neocommissures. Brain, 94, 327-336.

Sperry, R. W. (1974). Lateral specialisation in the surgically separated hemispheres 5-19. In The Neurosciences Third Study Program. Edited by F. O. Schmitt and F. G. Worden. MIT Press: Cambridge and London.

Zaidel, D., and Sperry, R. W. (1974). Memory impairment after commissurotomy in man. Brain, 97, 263-265.

Zangwill, O. L. (1974). Consciousness and the cerebral hemispheres. In Hemisphere Function in the Human Brain, pp. 264-278. Edited by S. J. Dimond and J. G. Beaumont. Elek Scientific Books: London. 